\title{
Forest management required for consistent carbon sink in China's forest plantations
}

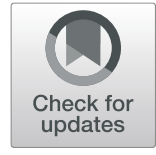

Zhen $\mathrm{Yu}^{1,2^{*}} \mathbb{D}$, Weibin You ${ }^{3}$, Evgenios Agathokleous ${ }^{1}$, Guoyi Zhou' ${ }^{1}$ and Shirong Liu ${ }^{2}$

\begin{abstract}
Background: Forest is the largest biomass carbon (C) pool in China, taking up a substantial amount of atmospheric carbon dioxide. Although it is well understood that planted forests (PFs) act as a large $C$ sink, the contribution of human management to $C$ storage enhancement remains obscure. Moreover, existing projections of forest $C$ dynamics suffer from spatially inconsistent age and type information or neglected human management impacts. In this study, using developed PF age and type maps and data collected from 1371 forest plantation sites in China, we simulated biomass $C$ stock change and quantified management impacts for the time period 2010-2050.

Results: Results show that future forest biomass C increment might have been overestimated by $32.5 \%-107.5 \%$ in former studies. We also found that age-related growth will be by far the largest contributor to PF biomass $\mathrm{C}$ increment from 2010 to $2050\left(1.23 \pm 0.002 \mathrm{Pg} \mathrm{C}, 1 \mathrm{Pg}=10^{15} \mathrm{~g}=1\right.$ billion metric tons), followed by the impact of human management $(0.57 \pm 0.02 \mathrm{Pg} \mathrm{C}$ ), while the contribution of climate is slight ( $0.087 \pm 0.04 \mathrm{Pg}$ C). Besides, an additional $0.24 \pm 0.07 \mathrm{Pg} C$ can be stored if current PFs are all managed by 2050, resulting in a total increase of $2.13 \pm 0.05 \mathrm{Pg} C$.

Conclusions: Forest management and age-related growth dominate the biomass $C$ change in PFs, while the effect of climatic factors on the accumulation is minor. To achieve the ambitious goal of forest $\mathrm{C}$ stock enhancement by $3.5 \mathrm{Pg}$ from 2020 to 2050, we advocate to improve the management of existing forests and reduce the requests for more lands for forest expansion, which helps mitigate potential conflicts with agricultural sectors. Our results highlight that appropriate planning and management are required for sustaining and enhancing biomass C sequestration in China's PF.
\end{abstract}

Keywords: Planted forest, Human management, Forest biomass carbon, Forest age, Forest expansion, Climate change

\section{Background}

Global forest absorbs carbon (C) equivalent to 34\% of the emission from fossil-fuel combustion and cement production, and biomass $\mathrm{C}$ augmentation plays a dominant role (Pan et al. 2011). For Chinese forests, approximately $80 \%-94 \%$ of the $\mathrm{C}$ sink lies in biomass, leaving only a minor fraction of sink in soil organic matter (Fang et al. 2001; Piao et al. 2009). Recent field-based surveys

\footnotetext{
* Correspondence: zyu@nuist.edu.cn

${ }^{1}$ Institute of Ecology, Jiangsu Key Laboratory of Agricultural Meteorology, Nanjing University of Information Science \& Technology, Nanjing 210044, China

${ }^{2}$ Key Laboratory of Forest Ecology and Environment, China's National Forestry and Grassland Administration, Institute of Forest Ecology, Environment and Protection, Chinese Academy of Forestry, Beijing 100091, China

Full list of author information is available at the end of the article
}

also confirmed that post-afforestation soil $\mathrm{C}$ sink was much smaller than biomass $\mathrm{C}$ sink, and even soil C loss was found after afforestation (Hong et al. 2020). Compared with relatively slow and variable $C$ stored in soil after tree-planting, biomass $\mathrm{C}$ accumulation in forest is more rapid and attainable than soil $\mathrm{C}$ enhancement. Since the Paris climate summit in 2015, it is increasingly advocated to accumulate $\mathrm{C}$ in terrestrial ecosystem as an efficient mitigation option (Rumpel et al. 2018), indicating that vegetation biomass is expected to contribute highly in compensating $\mathrm{C}$ emission. Besides, China has pledged to become $C$ neutral before 2060 at the UN General Assembly meeting in 2020, and forest C sink enhancement plays a fundamental role to achieve this ambitious goal. Therefore, many of the former studies have estimated the forest biomass $\mathrm{C}$ accumulation 
potential in China (Xu et al. 2010; He et al. 2017; Yao et al. 2018). Nonetheless, none of the former studies examined the human management impacts in determining future biomass $\mathrm{C}$ sink at a large scale. Existing projections of the biomass $\mathrm{C}$ changes in China's forests were attributed to either age-related growth or climatic factors (Xu et al. 2010; He et al. 2017; Yao et al. 2018). However, neglecting the role of human management impact can adversely affect sustainable $\mathrm{C}$ accumulation as the governments would be blindly guided to pursue PF's area expansion at the expense of forest tending and nursing. Therefore, clarifying the mechanisms and drivers of forest biomass $\mathrm{C}$ accumulation is a prerequisite not only for sustainable $\mathrm{C}$ sink, but also for diverting $\mathrm{C}$ from the atmosphere $\left(\mathrm{CO}_{2}\right)$ into terrestrial ecosystems.

A novel national-wide field campaign was conducted in China, in the framework of which thousands of samples were collected during 2011-2015. Field survey was performed in all 32 provinces, autonomous regions, and municipalities of mainland China, following a consistent and rigorous protocol (Tang et al. 2018). Based on the substantial number of samples collected, Tang et al. (2018) analyzed spatial distributions and drivers of C pools in China's forests; however, the human management impact was neglected in the $C$ sink projection subjected to a simple biomass-age relationship derived from pooling of all samples. This study aims to reveal forest biomass $\mathrm{C}$ accumulation potential as a function of human management impacts. Specifically, the directlymeasured data from the China-wide field campaign were revisited, filtered, and grouped for estimating the size, change, and potential of PF biomass $C$ in China since 2010. The results of this study provide a new perspective of the role of human interventions to maximizing the mitigation of atmospheric $\mathrm{CO}_{2}$, and can enlighten planning and management practices for sustaining and enhancing biomass $\mathrm{C}$ sequestration in China's PFs. These results can also enlighten the path toward achieving the UN SDGs for sustainable use of terrestrial ecosystems and forests management.

\section{Materials and methods}

\section{Field plot data}

A nationwide field campaign was conducted in China, during which site information was collected as detailed as possible, including geographical characteristics, soil properties, vegetation properties, disturbances, and human management (Yu et al. 2020a, b). Disturbances refer to impacts related to lack of management (see Additional file 1 Fig. S2 in Supporting Information), which may negatively affect forest growth, while "force majeure" disturbances were excluded (e.g. wind throw, lightning fire). This helps identifying signals of forest growth under lack of management, facilitating accurate projection of forest biomass $\mathrm{C}$ enhancement due to management. A total of 1371 forest plantation sites surveyed were selected for analysis, while the remaining sites were excluded due to missing information of forest age, vegetation biomass $\mathrm{C}$, disturbance, or management (Additional file 1, Figs. S1 and S2). Disturbances recorded included grazing, tourism, resin tapping, and treading, amongst others (Additional file 1 Fig. S2). Human management describes management types implemented (e.g. thinning, fertilization, irrigation, pesticide application, weeding, fencing, tending, and pruning), but details of the timing and frequency of management practices were not available. Thus, we divided the sites into two categories according to the presence or absence of human management. Sites that were not managed (including unmanaged sites influenced by disturbances) were allocated to the group "unmanaged", indicating the status of PF growth in the absence of management or exposure to a historical disturbance regime. For consistency with the use of forest maps reconstructed in a previous study (Yu et al. 2020a), we further grouped the sites into 17 major forests for each category (Additional file 1 Fig. S1, Table S1).

\section{Planted forest distribution and forest type maps}

The reliability of gridded map-based biomass $\mathrm{C}$ projections is largely determined by the reliability of forest age and type information, which is challenging for developing reliable gridded forest maps. Essentially, but often ignored, forest age map should be used in combination with the forest type information that the age map originated from forest biomass $\mathrm{C}$ estimation. This is understandable as forest age and type maps derived independently provide spatial mismatch of information, which may cause large biases if used together for biomass $\mathrm{C}$ simulations ( $\mathrm{Yu}$ et al. 2020a). To overcome the shortcomings in existing forest maps (e.g. inconsistent forest type and age information), we have developed a model for reconstructing spatially consistent, $1-\mathrm{km}$ resolution age and type maps of PFs in China (Yu et al. 2020a), facilitating accurate PF-specific $C$ sink estimations. More specifically, the maps were generated previously using multiple sources of data, including different land cover products (e.g. MODIS Land Cover Type, European Space Agency Climate Change Initiative Land Cover data, Global Forest Change 2000-2014 from Hansen et al. (2013)), the 6th, 7th, and 8th (1999-2013) national forest inventories, and the digitalized $\mathrm{PF}$ map produced by the State Forestry Administration of China. More details about the development of the maps can be found in Yu et al. (2020a).

The PF maps used in this study depict the distribution of forest stands only, while economic forests (for producing fruits, oil, spices, herbs, etc.) and bamboo forests 
were excluded. Since the PF age and type maps delineate the distribution of PF in 2005, we further updated the maps to 2010 in this study. More specifically, the new PFs from 2005 to 2010 were assigned ages (randomly from 1 to 5 years) and types in each province according to the 8th national forest inventory report. We also proportionally adjusted PF age maps to match the inventory reports for each province, which helps to reduce biases we identified previously (e.g. Fujian Province, Yu et al. 2020a). To this end, the age map grid cells are multiplied by the ratio of map-averaged forest age to inventory forest age for each province.

\section{Age-biomass equations}

Yao et al. (2018) proposed a series of models for forest biomass $\mathrm{C}$ growth simulation by taking into account the age and climate factors (i.e. mean annual air temperature and precipitation). In this study, we adopted a similar approach, but introduced elevation as an additional variable to the model to improve the biomass simulations (Additional file 1 Text S3, Table S3). Elevation is an essential variable highly correlated with chemical characteristics of both soil and atmosphere. Specifically, for each of the 17 grouped forest types, a climate- and elevationdependent exponential relationship between forest age and biomass $\mathrm{C}$ was used to obtain the best model fitted (Additional file 1 Table S4). The best fitted model for each PF type was identified as the model with the highest $R^{2}$ and lowest root mean square error (RMSE).

Two age-biomass relationships were generated using unmanaged and managed sites for each PF type. The relationships were implemented in simulations assuming that the PFs were managed differently from 2010 to 2050.

\section{Climate data}

Historical climate data (2000-2017) were spatially interpolated from 839 meteorological stations using the approach elaborated in $\mathrm{Yu}$ et al. (2019b). Future climate data were downloaded from CMIP5 of the World Climate Research Program (https://esgf-node.llnl.gov/ search/cmip5/). Climatic outputs of four Representative Concentration Pathways (RCP2.6, 4.5, 6.0, and 8.5) from eight earth system models were used, including HadGEM2-ES, IPSL-CM5A-LR, MPI-ESM-LR, GISS-E2R, GFDL-CM3, CanESM2, CSIRO-Mk3-6-0, and CNRM-CM5. The four pathways were adopted by the Intergovernmental Panel on Climate Change (IPCC). RCPs represent future radiative forcing trajectories, and higher RCP value indicates higher radiative forcing by $2100\left(2.6,4.5,6.0\right.$, and $\left.8.5 \mathrm{~W} \cdot \mathrm{m}^{-2}\right)$. The original outputs from the models were further interpolated into $1 \mathrm{~km} \times 1$ $\mathrm{km}$ using the Anusplin software (Ver. 4.1; Australian National University, Center for Resources and Environmental Studies, Canberra, Australia). We reconstructed future climate data by applying annual air temperature and precipitation change rate on the average of the historical period from 2000 to 2017 for each model output. This is to adjust the climate data using observed baseline year data to reduce estimation biases. The decadal averages of future annual air temperature and precipitation were used for forest biomass simulations for each RCP.

\section{Experimental design and statistical analysis}

In this study, we set up simulations to distinguish and quantify the effects of age, management, and climate on PF biomass C change in China from 2010 to 2050 (Additional file 1 Text S2, Table S2). For example, age effect is derived from experiments assuming that the PFs were not subjected to management (NOman, S1), while climate was fixed at the 2010s (Additional file 1 Table S2). More simulation experiments were designed, including business-as-usual management (BAUman, S2), all forest under management (ALLman, S3), and varying climate experiments (Additional file 1 Text S2, Table S2). In total, 8400 simulation experiments were performed [3 treatments (unmanaged, managed, BAU management $\times 100$ case runs (100 pairs of age and type maps reconstructed) $\times$ 8 earth system model $\times 3$ or 4 RCPs $=8400$ simulations]. It should be pointed out that, instead of quantifying the impact of a specific management practice, this study highlights the estimates of biomass $C$ accumulations at national scale by assuming the PFs were exposed to current or presumed managements and disturbances regimes. More specifically, the estimated $\mathrm{C}$ accumulation is derived from scenario simulations when the PFs were not managed or the national management intensity remained stable (business-as-usual scenario, BAU). Similarly, the C accumulation enhancement potential is the biomass $\mathrm{C}$ stock increment from applying current management intensity to the currently unmanaged PFs.

\section{Results}

Distribution of simulated biomass C in 2010

The simulated biomass $\mathrm{C}$ in PF was $4250.56 \pm 107.99 \mathrm{~g}$ $\mathrm{C} \cdot \mathrm{m}^{-2}$ for mainland China $(1.89 \pm 0.048 \mathrm{Pg} \mathrm{C}$ in total $)$ based on an average age of $19.71 \pm 0.013$ years in 2010 (Fig. 1). PF biomass $\mathrm{C}$ stock was higher in southern regions than in northern regions, and the highest biomass $\mathrm{C}$ stock was found in southeast regions (Fig. 1a). The uncertainty of biomass $C$ is relatively high in south regions, followed by northeast regions, while it was low in central regions (Fig. 1b).

\section{Projections of age, management, and climatic effects on forest biomass $\mathbf{C}$ accumulation}

Age effect is represented as the PF biomass $\mathrm{C}$ increment from experiment simulations with absence of management and climate change (experiment S1 in Additional 


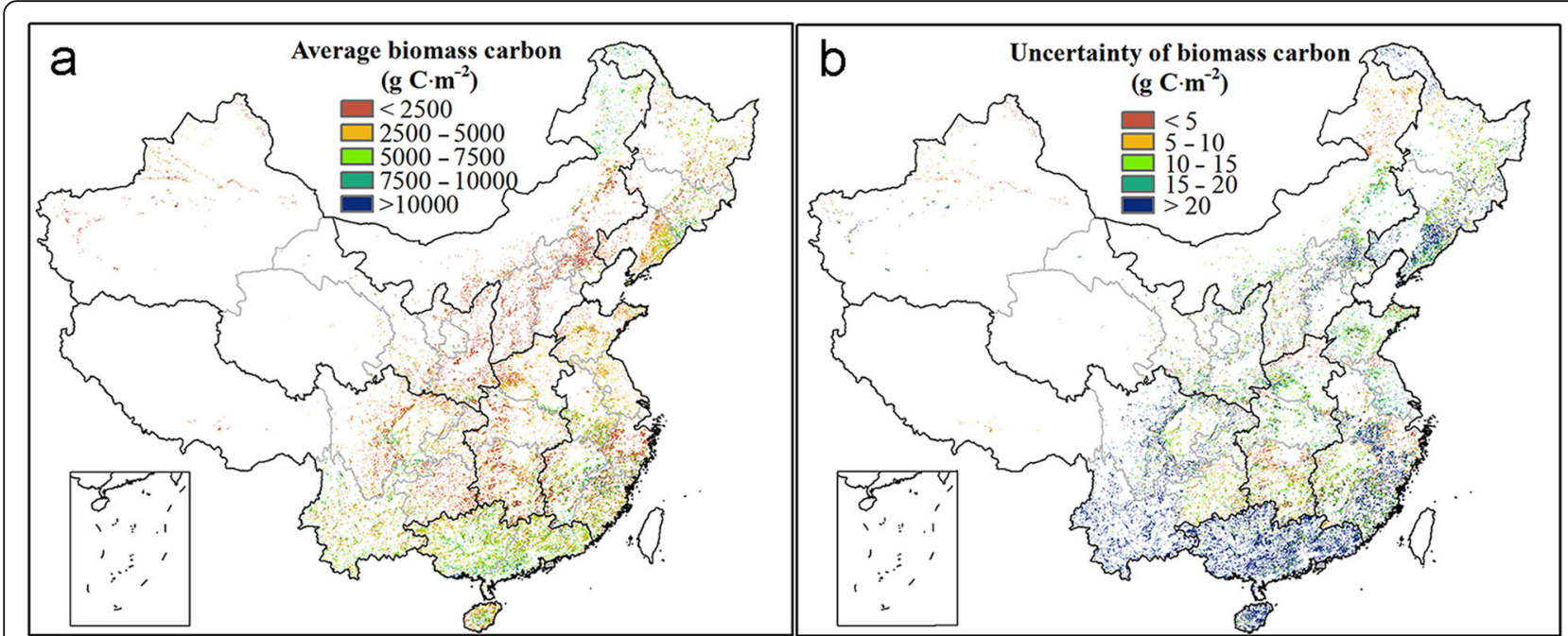

Fig. 1 Spatial distribution of simulated biomass carbon stock (a) and uncertainty (b) in forest plantations in 2010 (the uncertainty was derived from the 100 case runs using age and type maps reconstructed)

file 1, Table S2). Generally, the biomass C increments and uncertainties are higher in south and east regions than other regions of China (Fig. 2a). Similarly, the impacts of management on biomass $\mathrm{C}$ stock increment are also larger in south and east regions than central, western and north regions (experiment S2 in Additional file 1 Table S2, Fig. 2b). In comparison, climate change impact on biomass $\mathrm{C}$ relatively small. The climate effect on PFs for the period 2010-2050 is generally positive, and the national total impacts range between 0.038 to 0.138 Pg C (experiments S4 \& S1 in Additional file 1 Table S2, Fig. 2c).

\section{Projections of biomass $\mathrm{C}$ accumulation in planted forests}

The projected biomass C stock increment from 2010 to 2050 is predominantly contributed from age impact $(66.6 \%, 1.23 \pm 0.002 \mathrm{Pg} \mathrm{C})$, followed by management $(31.2 \%, 0.57 \pm 0.02 \mathrm{Pg} \mathrm{C})$, while the contribution of

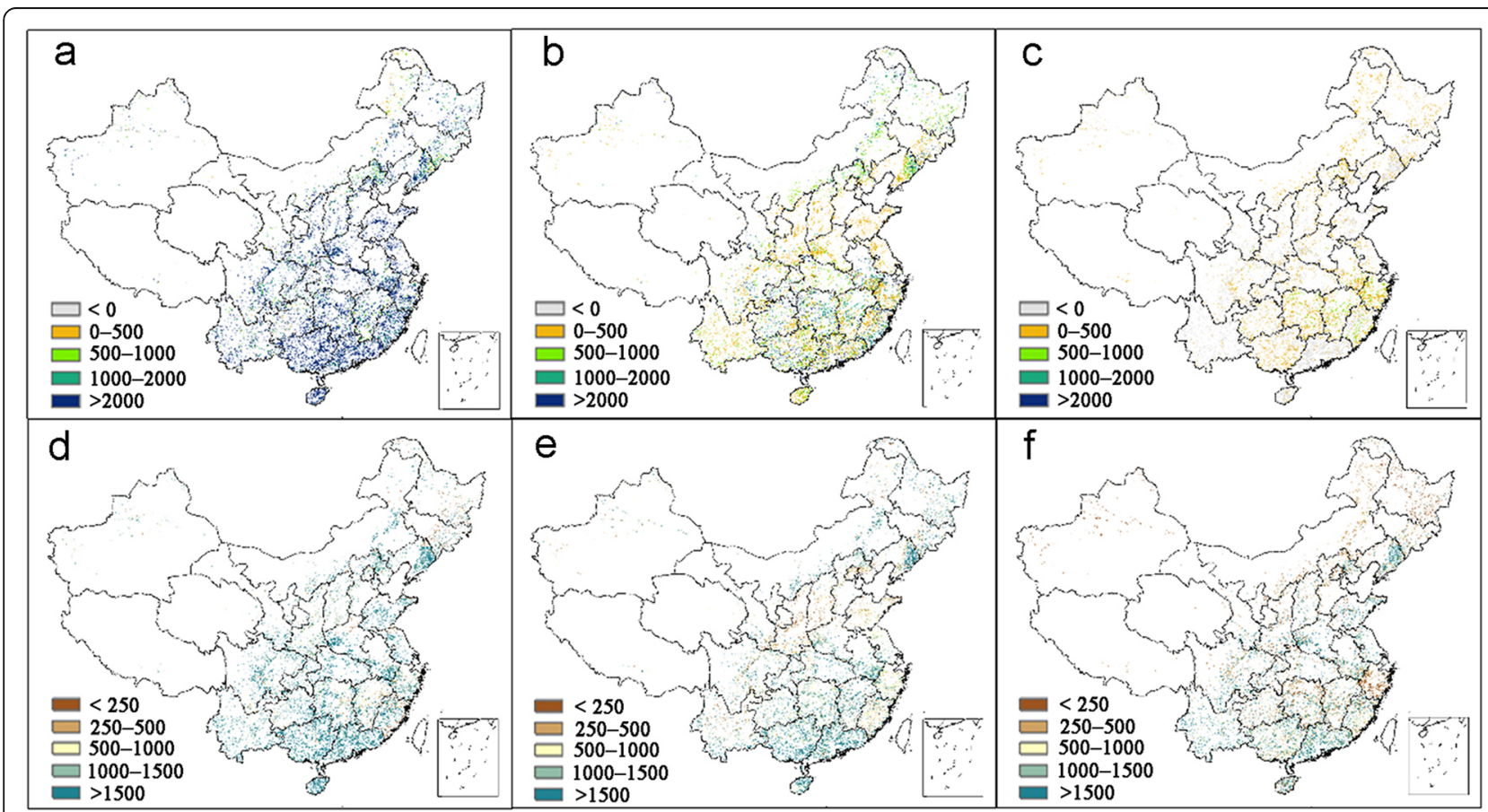

Fig. 2 Spatial distribution of (a) age, (b) management, and (c) climate impacts on biomass carbon stock accumulation from 2010 to 2050 in forest plantations (lower panel from left to right represent the uncertainties of age, management, and climate impacts, respectively; unit: $\mathrm{g} C \cdot \mathrm{m}^{-2}$ ) 
climate is only slight $(0.087 \pm 0.04 \mathrm{Pg}$ C) (Fig. 3). We also found that age, management, and climatic impacts decline quickly from 2010 to 2050 . Simulation results also revealed that an additional $0.24 \pm 0.07 \mathrm{Pg} \mathrm{C}$ could be stored if the unmanaged PFs were managed under current intensity, which is $13 \%$ of the $\mathrm{C}$ from the BAU management (Fig. 3).

Our simulations predicted that biomass $\mathrm{C}$ increment in China's PF would be 1.23-2.13 Pg C from 2010 to 2050, majorly depending on the management (Fig. 4). Specifically, under the BAU scenario (experiment S2, Additional file 1 Table S2), decadal biomass $\mathrm{C}$ increment would decrease from $0.75 \pm 0.12$ to $0.22 \pm 0.04 \mathrm{Pg} \mathrm{C}$ from 2010 to 2050, leading to a total of $1.80 \mathrm{Pg} \mathrm{C}$ stored in biomass (Fig. 4). Assuming the PFs will remain unmanaged (experiment S1), the total biomass $\mathrm{C}$ increment would be $1.23 \mathrm{Pg} \mathrm{C}$ until 2050 (age effect only). However, a total of 2.04 Pg C can be accumulated if the PFs were all managed (experiment S3, age and management effects plus management potential) (Fig. 4).

\section{Discussion}

\section{Simulated biomass $\mathrm{C}$ stock in PF}

Our estimation of the PF C stock $(1.89 \pm 0.048$ Pg C) was $16.44 \%-18.03 \%$ of the total forest biomass $\mathrm{C}$ in China (10.48-11.49 Pg C, 5568.5-5860 g C.m ${ }^{-2}$ ) (Tang et al. 2018; Xu et al. 2018). This is reasonable as PF was younger and generally had a lower $\mathrm{C}$ density compared with natural forest (Additional file 1 Text S4). Besides, our results were derived from simulations with considerable advance over prior studies. An important improvement is that the age, type, and distribution of the PFs have been strictly validated for each major forest type in each province (Yu et al. 2020a). Former studies generally suffered from lack of spatially matched information of forest characteristics (detail types, distributions) and demography (ages). Using mismatched forest age map and forest type map would introduce biases in the projection of forest growth because 1) only grid cells with both age and type present can be simulated, leading to a loss of forest area, and 2) forest age and type information would be inconsistent.

We extrapolated biomass $C$ increment in China's forests (6.71 Pg C in total during 2010-2050, Additional file 1 Table S5) and found that it is considerably lower than the range of 8.89-13.92 Pg C reported previously for the same period (He et al. 2017; Yao et al. 2018), albeit there was an evident overestimation in the extrapolation (Additional file 1 Text S5). This implies that former studies may have greatly overestimated the biomass $\mathrm{C}$ increment potential in China's forests by at least $32.5 \%$. Overestimations in previous studies may be attributed to the method and data used. An overestimation source is treating economic forests and bamboo forests as PFs, since the two forests have been classified as PF in the national inventory. Economic forests and bamboo forests, accounting for $10.5 \%-15.9 \%$ of the China's forest, contributed 9.8\% (186 Tg) biomass C increment from 1977 to 2008 (Guo et al. 2013). Nonetheless, the increment was almost solely attributed to area expansion, which rose from 1448 to 2579 Mha during the same period. Conversely, the average biomass $\mathrm{C}$ density in the two forests barely changed (1761 vs $1710 \mathrm{~g} \mathrm{C} \cdot \mathrm{m}^{-2}$ ) from 1977 to 2008, implying a relatively low biomass C increment potential from age effect alone. Thus, overestimations are expected if the two forests are treated the same

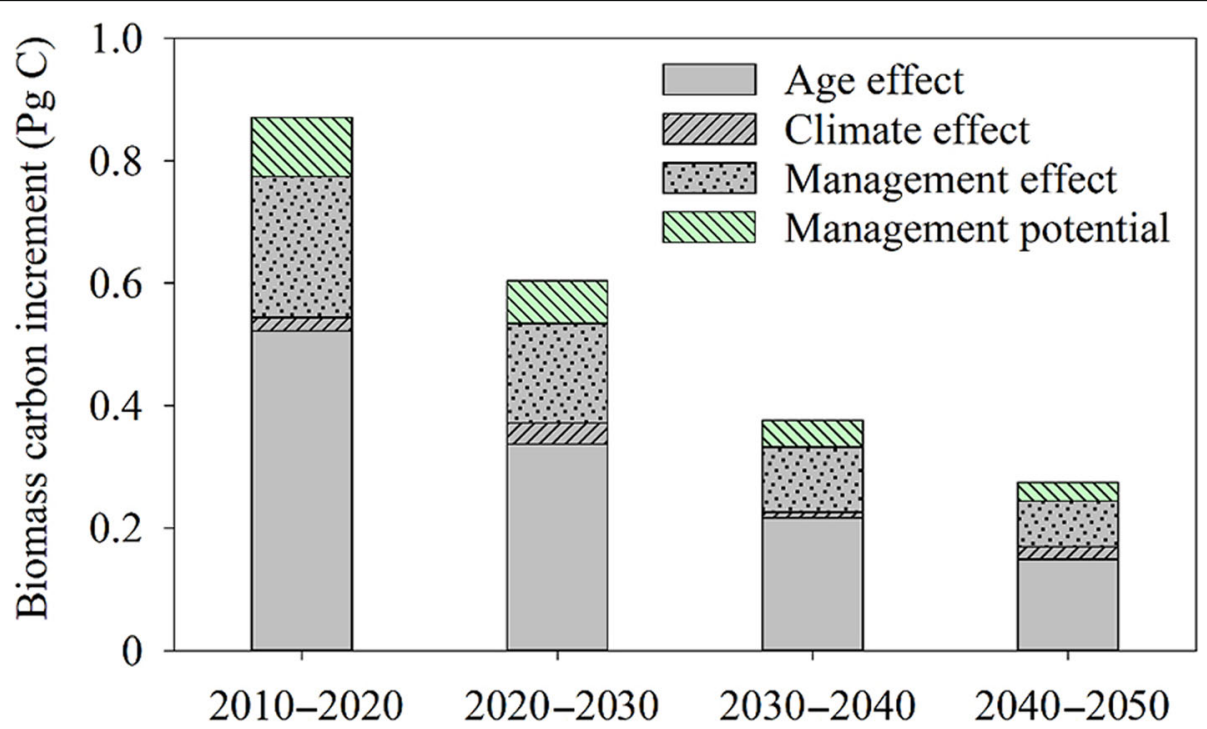

Fig. 3 Attribution of the effects of different factors on biomass carbon increment (Management effect: biomass carbon increment under bussiness-asusual management; Management potential: additioanl biomass carbon increment from manage of unmanaged forests; Unit: $\mathrm{Pg} C \cdot \mathrm{yr}^{-1}$ ) 


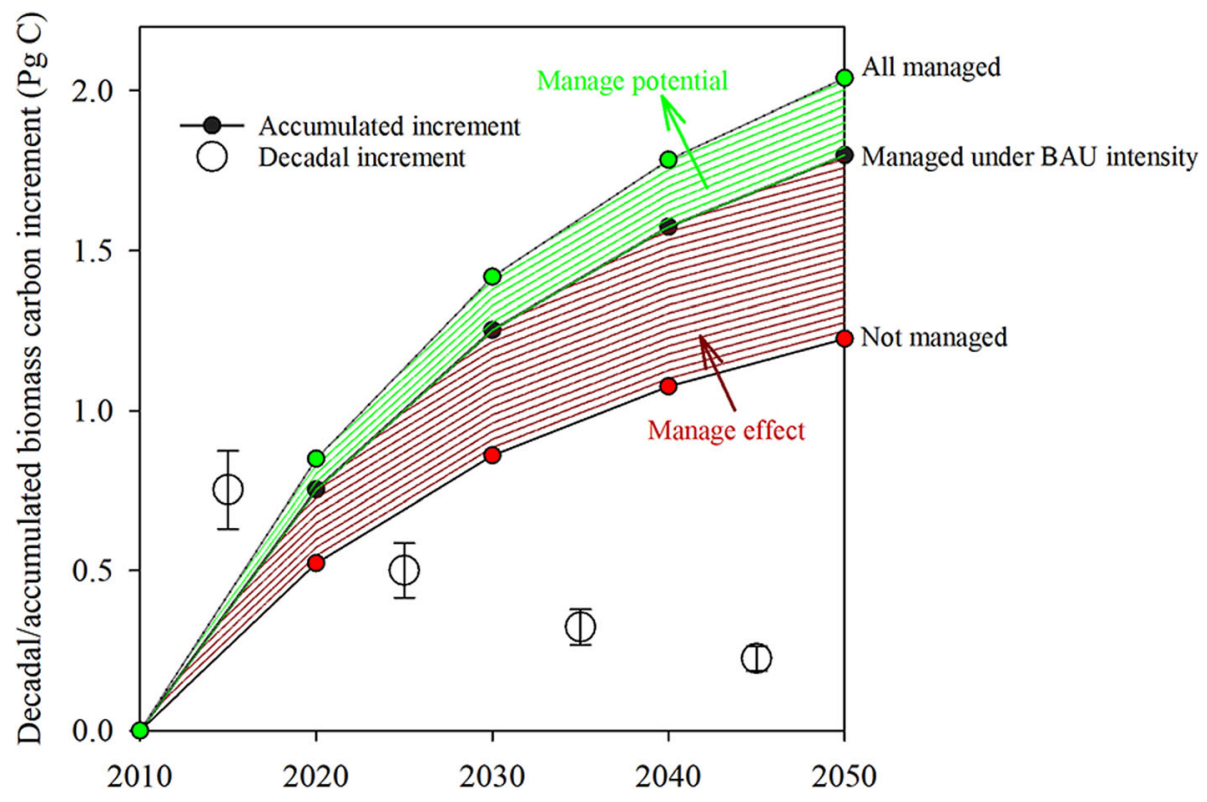

Fig. 4 Combined age and management effects on planted forest carbon stock increment under different managements since 2010 (shaded area: biomass carbon increment range under not managed and all managed scenarios; open circles indicate decadal biomass $\mathrm{C}$ increments; error bars indicate 1 standard deviation from the means)

using age-biomass relationships derived from samples obtained from other forests. Another source of overestimation may be sampling bias. Former studies rarely reported information about the management adopted in the sites used in developing age-biomass relationships. We found that using sites majorly sampled from intensively managed forest farm or timber forests would greatly overestimate forest $\mathrm{C}$ accumulation rate $(\mathrm{Yu}$ et al. 2020b). Due to the lack of management information, it is practically difficult to assess the samples used in previous studies.

China plans to further expand forest area by 49.49 Mha from 2021 to 2050 through afforestation to increase forest C stock by $3.5 \mathrm{Pg}$ (State Forestry Administration of the People's Republic of China 2016). However, our simulations revealed that this ambitious goal may be achievable by optimizing management of existing forests, thus preventing the use of additional land and potential conflicts with agricultural sectors.

Age and management effects on biomass $\mathrm{C}$ accumulation Impacts of age and management dominate the changes of the projected biomass $C$ stock increment from 2010 to 2050 (Fig. 3). Besides, the simulations also showed that age, management, and climatic impacts decline quickly from 2010 to 2050, which is consistent with other studies (He et al. 2017; Yao et al. 2018). We predicted that forest growth saturation would result into decline in decadal biomass $\mathrm{C}$ accumulation from $0.77 \pm$
0.12 in the 2010 s to $0.22 \pm 0.04 \mathrm{Pg} \mathrm{C}$ in the $2040 \mathrm{~s}$, contributing to a total biomass $\mathrm{C}$ increment of $1.84 \mathrm{Pg} \mathrm{C}$ (0.046 Pg C. $\mathrm{yr}^{-1}$ ) for the study period. Yao et al. (2018) and $\mathrm{Xu}$ et al. (2010) estimated that biomass C accumulation in China's forests would be around 0.14$0.16 \mathrm{Pg} \mathrm{C} \cdot \mathrm{yr}^{-1}$, which is approximately twice as high as the rate of $0.078 \mathrm{Pg} \mathrm{C} \cdot \mathrm{yr}^{-1}$ reported by $\mathrm{Hu}$ et al. (2015). Surprisingly, the estimation of $\mathrm{He}$ et al. (2017) is much higher (0.34 $\mathrm{Pg} \mathrm{C} \cdot \mathrm{yr}^{-1}$ ) during the same period, being likely overestimated due to no consideration of human management (He et al. 2017). Our simulated PF C increment is about $13.5 \%-59.0 \%$ of the increment of total forests reported. Despite a much lower area of PF compared to natural forest, $\mathrm{PF}$ has contributed a relatively high proportion (40.92\%) of forest C sink in China during 2004-2008 (Guo et al. 2013). Due to growth saturation, the simulated PFs $C$ sink is expected to decline quickly, which should be compensated by human intervention as suggested from our simulations.

Simulation results also revealed that an additional $0.24 \pm 0.07$ Pg C could be stored under all-management condition till 2050, which is $13 \%$ of the $\mathrm{C}$ from the management under BAU (Figs. 3 and 4). Among all the PF types, P. massoniana, Populus spp., and needle-leaf and broadleaf mixed forests will be the top three that would contribute $55 \%$ of the $\mathrm{C}$ biomass increment if all forests are managed, although the decadal contributions of the three PFs decrease from $0.040 \mathrm{Pg} \mathrm{C}$ in 2010 to $0.014 \mathrm{Pg} \mathrm{C}$ in 2050 (Additional file 1 Table S7). Since the effect of 
climate on biomass $\mathrm{C}$ is minor (Fig. 3, Additional file 1 Table S6), we focus on age and management effects hereafter.

Chinese forests have served as a strong $\mathrm{C}$ sink from both area expansion and forest growth in the last few decades (Zhao et al. 2019), while area expansion has been a larger contributor to $\mathrm{C}$ sink than forest growth in the PF $(62.2 \%$ vs $37.8 \%$, Li et al. (2016)). Wang et al. (2020) estimated the land biosphere sink at $-1.11 \pm 0.38$ $\mathrm{Pg} \mathrm{C} \cdot \mathrm{yr}^{-1}$ during 2010-2016, in which the progressively forested area in the southwest China (Yunnan, Guangxi and Guizhou provinces) played a pivotal role. Our study provides a similar result; however, the spatial distribution of $\mathrm{C}$ sink is not fully consistent with that of Wang et al. (2020). This is because Wang et al. (2020) adopted an atmospheric inversion approach, which captures $\mathrm{C}$ assimilated by the land ecosystem, including signals from timber harvested and exported to other regions. Especially for southern China, timber production is an essential industry in the region. In comparison, the biomass growth approach used in this study excludes the $C$ flux from timber production. A former study also revealed that the eight provinces in southern China (i.e. Fujian, Jiangxi, Zhejiang, Hunan, Guangdong, Guangxi, Sichuan, Yunnan), covering $20 \%$ of the land area, have contributed to approximately $51 \%$ of both area expansion and C stock increment in PFs since the 1970s ( $\mathrm{Li}$ et al. 2016). This is consistent with our simulations that the future biomass $\mathrm{C}$ increment potential locates mainly in the southern region (Fig. 1). Thus, continuous contribution from area expansion requires the availability of suitable land for afforestation, especially lands in the south.

However, the perspectives about PFs duration in C sequestration are divergent in China. Optimistic projections suggested a sustained $\mathrm{C}$ sink in PFs for the next few decades due to the young age (Huang et al. 2012; Deng et al. 2017), but a recent study suggested that forest growth saturation, land competition for food production, and soil-water depletion challenge the longevity of C sink (Tong et al. 2020). Our simulations predicted that biomass $\mathrm{C}$ increment in China's PF would be 1.23-2.13 Pg C from 2010 to 2050, primarily depending on management (Figs. 3 and 4). Therefore, proper forest management may be a promising approach to enhance $\mathrm{C}$ storage in China's PFs. For example, our previous study revealed that biomass $C$ accumulation in $P$. massoniana, C. lanceolata, and Eucalyptus sites was much faster in the presence of management compared to unmanaged sites (Yu et al. 2020b). Here, we found that an additional $0.24 \mathrm{Pg} \mathrm{C}$ can be stored if current PFs are all managed by 2050 . However, despite the additional $\mathrm{C}$ accumulation available from managements, the economic costs may be disproportionately high, indicating that enhancement of $\mathrm{C}$ storage in future PFs would be challenging.

\section{Implications for forest management targeted on biomass} $C$ accumulation

We found that the majority (65.3\%) of China's PFs were managed (Additional file 1 Fig. S2, Table S1), indicating that great efforts have been made by the government. Nevertheless, the impact of management on forest $\mathrm{C}$ accumulation has rarely been quantified in such a large scale and high spatial coverage in China, while its contribution to forest growth is usually attributed to age effect. For example, Yao et al. (2018) estimated that age-related forest biomass $\mathrm{C}$ storage would be $6.69 \mathrm{Pg} \mathrm{C}$ from the 2000 s to the 2040s, which actually included management impacts as the projection was derived from samples managed differently. Here, by dividing collected samples into managed and unmanaged groups, we developed biomass estimation models for each of the major PF types and quantified management impacts separately. Surprisingly, we found that management would be the second largest contributor to forest biomass $\mathrm{C}$ accumulation $(0.57 \pm 0.02 \mathrm{Pg} \mathrm{C})$ from 2010 to 2050, with an additional $42.1 \%(0.24 \pm 0.07 \mathrm{Pg} \mathrm{C})$ made possible if all forests are managed. This finding also implies that endeavors are required for maintaining or even enhancing C sink from China's PFs.

Appropriate planning and management, the endeavors expected to be devoted by government and foresters, should consider practices tailored to local climate and other ecological conditions. Despite a large number of sites surveyed and used in this study, more data are required to identify optimal management practices per PF type and for each location and forest type. Our results suggest that forest management and age-related growth dominate the biomass $\mathrm{C}$ change in PFs, while the effect of climatic factors on the accumulation is minor. This implies that management practices and forest demographic information, which have been under-represented in process-based models, are crucial for accurate simulations. Besides, due to the assumption that future forest growth from equilibrium conditions, current processbased models may fail to capture forest regrowth signal and, therefore, underestimate forest biomass $\mathrm{C}$ accumulation (Yao et al. 2018). For accurate attribution of historical management practice and projection of their effects on biomass $C$ change in China's PF, more controlled experiments are needed, and the field-derived results should be incorporated into model simulations.

To examine differences in management impacts between regions, we also quantified the sensitivity of biomass $C$ change in the ranges of air temperature and precipitation derived from the collected sites for each $\mathrm{PF}$. The sensitivity was described as biomass $\mathrm{C}$ change from the 2010s to the 2040s between managed and unmanaged regimes. We found that management impact in most of the PF types was sensitive to temperature, 
except for Pinus tabulaeformis and $P$. elliottii (Additional file 1 Fig. S4). For the major $C$ increment contributor, $P$. massoniana, management impact on biomass $\mathrm{C}$ increment was higher in warmer and wetter regions (Additional file 1 Fig. S4). Regarding Populus and $C$. lanceolata, management impact on biomass $\mathrm{C}$ increment was positive and higher in warmer areas, indicating a higher $\mathrm{C}$ storage potential from management in warmer areas. Conversely, management impact on Pinus tabulaeformis and $P$. elliottii was more sensitive to precipitation, implying a higher $\mathrm{C}$ uptake potential from PF management in wetter regions. Thus, although management helps enhancing $C$ uptake in PFs, its impacts will be influenced by climate change.

\section{Uncertainties}

There are some uncertainties that may affect the results of this study. First, we did not separate contributions from rising $\mathrm{CO}_{2}, \mathrm{~N}$ deposition, and distrubances such as fire and diseases. Since the sites collected have been exposed to these atmospheric, climatic, and other environmental factors, their impacts have been reflected in PFs's growth. Thus, our simulations assume that these factors will remain the same as with the historical period. Yao et al. (2018) revealed that the effect of rising $\mathrm{CO}_{2}$ concentration on biomass $C$ accumulation would be $25 \%-47 \%$ of the age effect. Similarly, $\mathrm{N}$ deposition may promote forest $\mathrm{C}$ stock increment, albeit the effects differ between locations and forest types (Nadelhoffer et al. 1999; Thomas et al. 2010; Schulte-Uebbing and de Vries 2018). However, Yu et al. (2019a) found that atmospheric N deposition in China has been stabilized over the past decade due to joint contribution from changes in the socioeconomic structure and vigorous controls in $\mathrm{N}$ pollution. Thus, stabilized $\mathrm{N}$ deposition combined with other natural disturbances (e.g. pests, fires, droughts) are likely to offset the contribution from rising atmospheric $\mathrm{CO}_{2}$, although the net impact is obscure.

Second, China will continue to expand its plantation area for environmental improvement and C sequestration facilitation (Wang et al. 2007; Ouyang et al. 2016; Lu et al. 2018). According to the National Forest Management and Planning (State Forestry Administration of the People's Republic of China 2016), projected forest cover will increase to $26 \%$, with forest $C$ stock increasing to $13 \mathrm{Pg}$ by 2050, suggesting another 49.49 Mha will be forested from 2021 to 2050 . Our simulations, by adopting a fixed forest distribution map, suggest that the goal of $\mathrm{C}$ stock enhancement is feasible through a better management of current forests alone, without requiring more lands. Although a higher $\mathrm{C}$ uptake could be expected, the economic costs of expanding PF area should be examined due to challenges from the rising logistical costs, unfavorable environmental conditions, and fragmented lands (Yu et al. 2019b).
Third, the forest management potential may be lower than estimated because China's PFs are serviceorientated so that management practices and intensity implemented should be tailored to meet the foremost goal. For example, the Three-North Shelter Forest Program launched in the late 1970 s aiming to alleviate soil degredation and sandstorm, while the Grain for Green Program was initiated in 2000 to protect croplands in hilly areas by reducing soil erosion and flood risk ( $\mathrm{Lu}$ et al. 2018). Thus, the management of these forests are different from the aim of timber production, which was fast growth and high yield of forest under intensive management. Despite the differing goals, appropriate planning and management are required to reduce tree mortality while encouraging forest quality enhancement.

\section{Conclusions}

To our knowledge, this is the first study to quantify the impact of human management on biomass $C$ accumulation at such a broad scale. Our simulation results revealed that human management is the second largest contributor to PF biomass C increment (46.34\% of agerelated growth). To achieve the ambitious goal of " $\mathrm{C}$ neutral" before 2060 as promised at the United Nations General Assembly in 2020, China plans to further expand forest area by 49.49 Mha to increase forest C stock by $3.5 \mathrm{Pg}$ from 2021 to 2050 . However, our simulations suggest that the goal of $\mathrm{C}$ stock enhancement is feasible through better management of current forests alone, without requiring more land expansion. Thus, appropriate planning and management should be stressed for sustaining and enhancing biomass $\mathrm{C}$ sequestration in China's PF.

\section{Supplementary Information}

The online version contains supplementary material available at https://doi. org/10.1186/s40663-021-00335-7.

\section{Additional file 1.}

\section{Acknowledgments}

We thank Dr. Pengsen Sun and Dr. Chaoqun Lu for helps in language editing and providing suggestions to improve the manuscript. We also thank field data collection efforts from Jingyun Fang, Guirui Yu, Xuli Tang, Junhua Yan, Gengxu Wang, Keping Ma, Shenggong Li, Sheng Du, Shijie Han, Youxin Ma, Deqiang Zhang, Juxiu Liu, Shizhong Liu, Guowei Chu, Qianmei Zhang, Yuelin Li.

\section{Authors' contributions}

ZY and GZ conceived the idea. ZY analyzed the data. ZY, SL, WY, and EA drafted the manuscript. All authors commented preliminary versions of the manuscript and contributed to improve the final version. All authors read and approved the final manuscript.

\section{Funding}

This work was supported by the National Science Foundation of China (No. 32001166), Jiangsu Key Laboratory of Agricultural Meteorology Foundation (JKLAM2004), and the Startup Foundation for Introducing Talent of NUIST (No. 2019r059). 


\section{Availability of data and materials}

The data that support the findings of this study are available from the corresponding author upon reasonable request.

\section{Declarations}

Ethics approval and consent to participate

Not applicable.

\section{Consent for publication}

Not applicable.

\section{Competing interests}

The authors declare that they have no competing interests.

\section{Author details}

'Institute of Ecology, Jiangsu Key Laboratory of Agricultural Meteorology, Nanjing University of Information Science \& Technology, Nanjing 210044, China. ${ }^{2}$ Key Laboratory of Forest Ecology and Environment, China's National Forestry and Grassland Administration, Institute of Forest Ecology, Environment and Protection, Chinese Academy of Forestry, Beijing 100091, China. ${ }^{3}$ College of Forestry, Fujian Agriculture and Forestry University, Fuzhou 350002, China

Received: 20 April 2021 Accepted: 5 July 2021

Published online: 10 August 2021

\section{References}

Deng L, Liu S, Kim DG, Peng C, Sweeney S, Shangguan Z (2017) Past and future carbon sequestration benefits of China's grain for green program. Glob Environ Chang 47:13-20. https://doi.org/10.1016/j.gloenvcha.2017.09.006

Fang J, Chen A, Peng C, Zhao S, Ci L (2001) Changes in forest biomass carbon storage in China between 1949 and 1998. Science 292(5525):2320-2322. https://doi.org/10.1126/science.1058629

Guo Z, Hu H, Li P, Li N, Fang J (2013) Spatio-temporal changes in biomass carbon sinks in China's forests from 1977 to 2008. Sci China Life Sci 56(7): 661-671. https://doi.org/10.1007/s11427-013-4492-2

Hansen MC, Potapov PV, Moore R, Hancher M, Turubanova SA, Tyukavina A, Thau D, Stehman SV, Goetz SJ, Loveland TR, Kommareddy A, Egorov A, Chini L, Justice CO, Townshend JRG (2013) High-resolution global maps of 21stcentury forest cover change. Science 342(6160):850-853. https://doi.org/1 $0.1126 /$ science. 1244693

He N, Wen D, Zhu J, Tang X, Xu L, Zhang L, Hu H, Huang M, Yu G (2017) Vegetation carbon sequestration in Chinese forests from 2010 to 2050. Glob Chang Biol 23(4):1575-1584. https://doi.org/10.1111/gcb.13479

Hong S, Yin G, Piao S, Dybzinski R, Cong N, Li X, Wang K, Peñuelas J, Zeng H, Chen A (2020) Divergent responses of soil organic carbon to afforestation. Nat Sustain 3(9):694-700. https://doi.org/10.1038/s41893-020-0557-y

Hu H, Wang S, Guo Z, Xu B, Fang J (2015) The stage-classified matrix models project a significant increase in biomass carbon stocks in China's forests between 2005 and 2050. Sci Rep 5(1):11203. https://doi.org/10.103 8/srep 11203

Huang L, Liu J, Shao Q, Xu X (2012) Carbon sequestration by forestation across China: past, present, and future. Renew Sust Energ Rev 16(2):1291-1299. https://doi.org/10.1016/..rser.2011.10.004

Li P, Zhu J, Hu H, Guo Z, Pan Y, Birdsey R, Fang J (2016) The relative contributions of forest growth and areal expansion to forest biomass carbon. Biogeosci 13(2):375-388. https://doi.org/10.5194/bg-13-375-2016

Lu F, Hu H, Sun W, Zhu J, Liu G, Zhou W, Zhang Q, Shi P, Liu X, Wu X, Zhang L, Wei X, Dai L, Zhang K, Sun Y, Xue S, Zhang W, Xiong D, Deng L, Liu B, Zhou L, Zhang C, Zheng X, Cao J, Huang Y, He N, Zhou G, Bai Y, Xie Z, Tang Z, Wu B, Fang J, Liu G, Yu G (2018) Effects of national ecological restoration projects on carbon sequestration in China from 2001 to 2010. PNAS 115(16):40394044. https://doi.org/10.1073/pnas.1700294115

Nadelhoffer KJ, Emmett BA, Gundersen P, Kjønaas OJ, Koopmans CJ, Schleppi P, Tietema A, Wright RF (1999) Nitrogen deposition makes a minor contribution to carbon sequestration in temperate forests. Nature 398(6723):145-148. https://doi.org/10.1038/18205

Ouyang Z, Zheng H, Xiao Y, Polasky S, Liu J, Xu W, Wang Q, Zhang L, Xiao Y, Rao E, Jiang L, Lu F, Wang X, Yang G, Gong S, Wu B, Zeng Y, Yang W, Daily GC
(2016) Improvements in ecosystem services from investments in natural capital. Science 352(6292):1455-1459. https://doi.org/10.1126/science.aaf2295

Pan Y, Birdsey RA, Fang J, Houghton R, Kauppi PE, Kurz WA, Phillips OL, Shvidenko A, Lewis SL, Canadell JG, Ciais P, Jackson RB, Pacala SW, McGuire AD, Piao S, Rautiainen A, Sitch S, Hayes D (2011) A large and persistent carbon sink in the world's forests. Science 333(6045):988-993. https://doi. org/10.1126/science. 1201609

Piao S, Fang J, Ciais P, Peylin P, Huang Y, Sitch S, Wang T (2009) The carbon balance of terrestrial ecosystems in China. Nature 458(7241):1009-1013. https://doi.org/10.1038/nature07944

Rumpel C, Amiraslani F, Koutika LS, Smith P, Whitehead D, Wollenberg E (2018) Put more carbon in soils to meet Paris climate pledges. Nature 564(7734):3234. https://doi.org/10.1038/d41586-018-07587-4

Schulte-Uebbing L, de Vries W (2018) Global-scale impacts of nitrogen deposition on tree carbon sequestration in tropical, temperate, and boreal forests: a metaanalysis. Glob Chang Biol 24(2):e416-e431. https://doi.org/10.1111/gcb.13862

State Forestry Administration of the People's Republic of China (2016) National forest management and planning (2016-2050). China Forestry Publishing House, Beijing (in Chinese)

Tang X, Zhao X, Bai Y, Tang Z, Wang W, Zhao Y, Wan H, Xie Z, Shi X, Wu B, Wang G, Yan J, Ma K, Du S, Li S, Han S, Ma Y, Hu H, He N, Yang Y, Han W, He H, Yu G, Fang J, Zhou G (2018) Carbon pools in China's terrestrial ecosystems: new estimates based on an intensive field survey. PNAS 115(16):4021-4026. https://doi.org/10.1073/pnas.1700291115

Thomas RQ, Canham CD, Weathers KC, Goodale CL (2010) Increased tree carbon storage in response to nitrogen deposition in the US. Nat Geosci 3(1):13-17. https://doi.org/10.1038/ngeo721

Tong X, Brandt M, Yue Y, Ciais P, Rudbeck Jepsen M, Penuelas J, Wigneron JP, Xiao X, Song XP, Horion S, Rasmussen K, Saatchi S, Fan L, Wang K, Zhang B, Chen Z, Wang Y, Li X, Fensholt R (2020) Forest management in southern China generates short term extensive carbon sequestration. Nat Commun 11(1):129. https://doi.org/10.1038/s41467-019-13798-8

Wang G, Innes JL, Lei J, Dai S, Wu SW (2007) Ecology: China's forestry reforms. Science 318(5856):1556-1557. https://doi.org/10.1126/science.1147247

Wang J, Feng L, Palmer PI, Liu Y, Fang S, Bösch H, O'Dell CW, Tang X, Yang D, Liu L, Xia CZ (2020) Large Chinese land carbon sink estimated from atmospheric carbon dioxide data. Nature 586(7831):720-723. https://doi.org/10.1038/s41 586-020-2849-9

Xu B, Guo ZD, Piao SL, Fang JY (2010) Biomass carbon stocks in China's forests between 2000 and 2050: a prediction based on forest biomass-age relationships. Sci China Life Sci 53(7):776-783. https://doi.org/10.1007/s11427010-4030-4

Xu L, Yu G, He N, Wang Q, Gao Y, Wen D, Li S, Niu S, Ge J (2018) Carbon storage in China's terrestrial ecosystems: a synthesis. Sci Rep 8(1):2806. https://doi. org/10.1038/s41598-018-20764-9

Yao Y, Piao S, Wang T (2018) Future biomass carbon sequestration capacity of Chinese forests. Sci Bull 63:1108-1117

Yu G, Jia Y, He N, Zhu J, Chen Z, Wang Q, Piao S, Liu X, He H, Guo X, Wen Z, Li P, Ding G, Goulding K (2019a) Stabilization of atmospheric nitrogen deposition in China over the past decade. Nat Geosci 12(6):424-429. https://doi.org/10.1 038/s41561-019-0352-4

Yu Z, Liu S, Wang J, Wei X, Schuler J, Sun P, Harper R, Zegre N (2019b) Natural forests exhibit higher carbon sequestration and lower water consumption than planted forests in China. Glob Chang Biol 25(1):68-77. https://doi.org/1 $0.1111 / \mathrm{gcb} .14484$

Yu Z, Zhao H, Liu S, Zhou G, Fang J, Yu G, Tang X, Wang W, Yan J, Wang G, Ma K Li S, Du S, Han S, Ma Y, Zhang D, Liu J, Liu S, Chu G, Zhang Q, Li Y (2020a) Mapping forest type and age in China's plantations. Sci Total Environ 744: 140790. https://doi.org/10.1016/j.scitotenv.2020.140790

Yu Z, Zhou G, Liu S, Sun P, Agathokleous E (2020b) Impacts of forest management intensity on carbon accumulation of China's forest plantations. Forest Ecol Manag 472:118252. https://doi.org/10.1016/j.foreco.2020.118252

Zhao M, Yang J, Zhao N, Liu Y, Wang Y, Wilson JP, Yue T (2019) Estimation of China's forest stand biomass carbon sequestration based on the continuous biomass expansion factor model and seven forest inventories from 1977 to 2013. Forest Ecol Manag 448:528-534. https://doi.org/10.1016/j.foreco.2019.06.036 